\title{
DEVELOPMENT OF DEMATEL AND ANP METHOD FOR THE PLANNING PROCESS OF AMPHIBIOUS OPERATION
}

\author{
Ahmadi, \\ Yudy Arie Bintoro \\ Department of Industrial Engineering \\ Indonesion Naval College of Technology \\ ahmadi_raha@yahoo.com \\ Yudy Arie Bintoro \\ Department of Industrial Engineering \\ Indonesion Naval College of Technology
}

\begin{abstract}
Amphibious Operations Planning Process follows 14-step process of decision-making according to military doctrine Books of TNI (Indonesian Armed Forces) Joint Operations. $7^{\text {th }}$ (seventh) step of the decision-making process in Amphibious Operations planning is implementing Course of Action (CoA) comparison. Course of Action is an individual plan or Commander who will complete or in connection with the completion of a mission. Comparison of CoA is very important because the best CoA would be a reference for the preparation of the Plan of Operations which would be turned into Command Operations. Thus the staff could use some of the techniques/methods of decision making that can produce the best recommendation of $\mathrm{CoA}$, so the Commander can make the best decision anyway.

Decision making of the best CoA will consider many criteria in it. Therefore in this study used methods Decision Making Trial And Evaluation Laboratory (DEMATEL) and Analytic Network Process (ANP) which can be used in solving problems with many criteria or Multiple Criteria Decision Making (MCDM). DEMATEL method is used to obtain the consideration of decision making by knowing the relationship interrelations among criteria or aspects. While the ANP method is used to determine the value of alternative priority weights based on models derived from the DEMATEL method.

The results of this study are the form of criteria and sub-criteria which affect the CoA comparison, the relationship between the criteria/sub-criteria and main subcriteria priority weight values obtained from the results of data processing. The main sub-criterias based on the largest weight value of each criteria are Mobility (Criteria for Operating), Logistics Support System (Criteria for Logistics), Victims Approximating (Criteria for Personnel) and Enemy Detection (Criteria for Electronic Communications).
\end{abstract}

Keywords: Decision Making And Trial Evaluation Laboratory (DEMATEL), the Analytical Network Process (ANP), Course of Action (CoA), Main Subcriterias.

\section{Introduction.}

Planning is a process that important in support of decision-making would be done by leaders. In which it is contained an action to ensure that the decision will be taken is really have been appropriate for solving a problem or accomplishment of a purpose. Hence to produce a very important decision, moreover, have a significant effect, required a stages or processing must be implemented so that produced the right decision and can be executed with proper as well. The Military Campaign is a series some Joint Operation very closely related to the Military Decision Making Process (MDMP) in produce a military campaign plan. The Military Campaign Plan represent the series of Joint Operation planned by Joint Command on a operation territory being determined. The Military Campaign Plan is the result of the planning process of Joint Operation to face contingency, namely crisis based approximate military strategy that is part of a National Strategy (Doctrine of the Military Campaign, 2013).

Substantially, a military operation carried out by Indonesian Armed Forces (TNI) there is no done individually by one force, but involving the combined force in land, sea and air. One of a military operation is an Amphibious Operation integrating various kinds of power, namely ships, aircrafts and the Mariners in an offensive to the enemy beach and or potentially pre-sighted the enemy (The TNI Doctrine of Amphibious Operation, 2013). An Amphibious Operation is conducted by the Task Command of Joint Amphibious Operation that consists of three main force namely Sea Task Command, Air Task Command and Mariners Force with the variables power stations.

In the planning process of an Amphibious Operation follows the rules of 14 steps that have poured in the TNI Doctrine of Joint Operation (The TNI Doctrine of Joint Operation, 2013). Steps of decision-making process in the level of Joint Task Command, one of which is the Joint Task Command of Amphibious Operation, is analogous/identical /same by steps of decision-making process in the level of Joint Command (The TNI Doctrine of Joint Operation, 2013). Thus the decision taken from the Higher Command can be implemented by Lower Command under in accordance with step has been set. 
The 7th step of the decision-making process in Amphibious Operation planning is carrying out comparisons of Course of Action (CoA). Course of Action is an individual plan or a Commander who will finish or in connection with the completion of a mission (Doctrine of Military Campaigns, 2013). Some alternatives of CoA will be chosen, having regard to a number of criteria have been determined, to obtain the best CoA. Comparison of the CoA is very important becaue later the best CoA will be the reference for the preparation of Plan of Operations which will then be transformed into Command Operations. Thus the staff could use some of the techniques/methods of decision making that can produce the best recommendations, so that the Commander can make the best decision.

Currently, comparison of the CoA is done by way of combining quantitative method (Numerical Analysis) and qualitative methods (Broad Categories, profit/loss and risk analysis). The quantitative assessment will be more easy because it has a clearer size compared then qualitative assessment. Numerical Analysis methods used in the comparison of CoA is a form of quantitative Decision method of Matrix Approach. An example of this form of calculation by the method described by Table 1.1 regarding the selection of a contractor below.

Tabel 1.1 Decision Matrix for the Contractor Selection Problem

\begin{tabular}{|l|c|c|c|c|}
\hline \multirow{2}{*}{ Criterion } & \multirow{2}{*}{ Weight } & \multicolumn{4}{|c|}{ Rating of Contractor on a 10-Point } \\
& & \multicolumn{4}{|c|}{ Scale } \\
\cline { 3 - 5 } & & Contracto & Contracto & Contractor \\
& & 9 & 6 & 3 \\
\hline Contract Value & 10 & 8 & 9 & 6 \\
\hline Lead Time & 7 & 7 & 8 & 9 \\
\hline Competence & 6 & 6 & 7 & 8 \\
\hline Dependability & 8 & 236 & 227 & 210 \\
\hline Weighted Sum & & 1 & 2 & 3 \\
\hline Ranking & & \multicolumn{5}{|c}{} \\
\hline
\end{tabular}

Source: (Military Operations Research:

Quantitative Decision Making, N.K Jaiswal 1997)

According to Jaiswal in his book was explained that the use of this method were weakness. The first one is the weight given to each contracting still subjective and biased and had no way to reduce it. Then the second is giving weights to each criteria not using methods in scientific and someone must use intuition and experience in providing the weight (N.K. Jaiswal, 1997). It will certainly affect an objective analyzer against selecting alternative exists. In this research writers strove for ascertaining the relations and degrees of distinction influence among criteria in comparison CoA (Course of Action) using DEMATEL method. The result of DEMATEL is used as basis in determination of weights to choose the best CoA (Course of Action) using ANP method. Using that object because there are no have been reviewed by researchers before. Besides, DEMATEL and ANP method also have not used in support of decision on a planning process of an Amphibious Operation.

\section{Literature Review.}

\subsection{Military Decision Making Process}

Military decision-making process is the way to find out how to take a decision, when and what judgment between including in it to find out the consequences of the decision taken. Decision-making process in Indonesian Armed Forces (TNI) follows the rules of 14 steps that have poured in the TNI Doctrine of Joint Operation (The TNI Doctrine of Joint Operation 2013). It became a doctrine for TNI so as to achieve a common think and act in plan for an activity a military operation. Thus decision-making process can be applied in all the activity of operating especially an operation implemented by Joint Force, that is, land, sea and air. Decision-making process is composed of fourteen steps with the sequence of as follows:

1. Received the assignment.

2. Mission Analysis.

3. Carry out a preliminary meeting of a Task analysis Briefing by the staff of the Commander.

4. Delivery of Joint Commander instructions planning and early warning command to down units.

5. Course Of Action Development.

6. Course Of Action Analysis.

7. Course Of Action Comparing.

8. Course Of Action Decision Briefing (staff) and the selection of the best Course Of Action.

9. Decision and a general concept of an operation.

10. The preparation of the plan outline.

11. The preparation of the concept of operations plan.

12. Testing operation plans.

13. Arrange the operation plan paper which has been tested and distributed.

14. Supervison and Feed back. 
2.2 Joint Operations. The types of joint operation included in a military operation of war are as follows:
1. Air Traffic Operation.
2. Amphibious Operation.
3. Coast Defence Operation.
4. Air Defense Operation.
5. Joint Naval Operation.
6. Joint Army Operation.
7. Administration Landing Operation.

\subsection{Amphibious Operation}

An amphibious operation substantially is an operation that integrating various kinds of power, namely a ship, aircraft and the Mariners offensive to the enemy shore or which is controlled by the enemy (The TNI Doctrine of an Amphibious Operation, 2013). Because a Joint Operation, and then in the implementation of an Amphibious Operation would be formed a joint task command called Joint Task Command of Amphibious Operation led by a Commander of Joint Task Command of Amphibious Operation.

\section{Methodology.}

\subsection{Preparation Phase.}

At this stage undertaken the formulation of a problem, the purpose of the research, the study of Literature, and Preview System

\subsection{Implementation Phase.}

At this stage the activities implemented in the form of Data collection, determination of Criterias and Subcriterias, Data processing using DEMATEL and Software Super Decison, implementation, carry out the analysis and Interpretation of the results of the data processing.

\subsection{Final Phase.}

At this stage was carried out after the completion of the conclusion of the process of retrieval processing and data analysis. Conclusions drawn should be able to answer the problem formulation has been formulated in Chapter 1. In addition at this stage also delivered advice that can be used by next researchers.

\section{Model/Data Analysis.}

\subsection{The decisive criteria in the selection of the best course of action.}

Based on some of the Assistant who carry out the analysis of Course of Action (CoA) alternative and brainstorming with the experts then got criterias and subcriterias for the best CoA are like in the figure below:

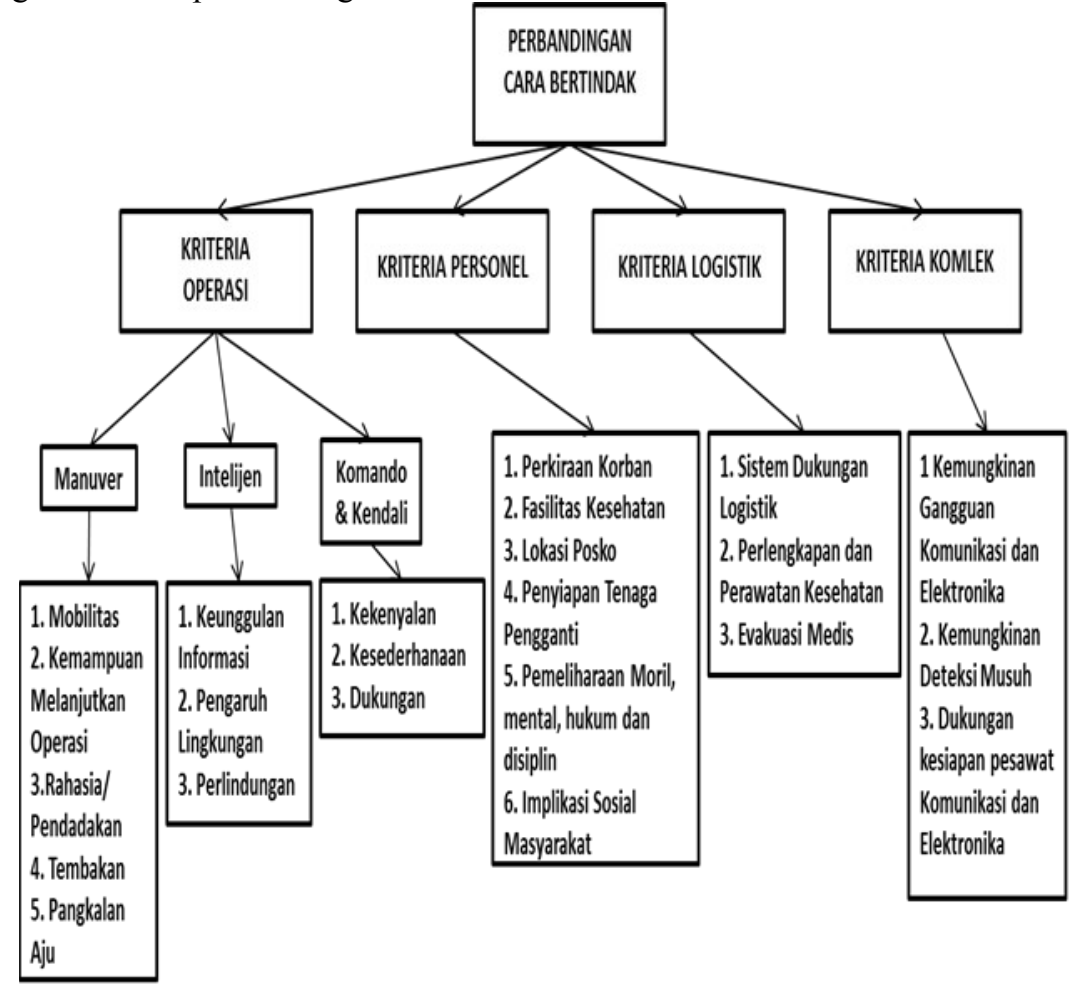


Figure 4.1 Course of Action Criterias

\subsection{Decision Making Trial And Evaluation Laboratory (DEMATEL)}

DEMATEL method applied to know the description of relationships that occur in the criterias and subcriterias on the selection the best CoA alternatives in Amphibious Operations Planning Procedures. The calculation data of a questionnaire filled by the persons that is considered the expert in the field of Amphibious Operations have met the qualification requirements. The result of the processing of DEMATEL is in the form of the impact relation (IRM) that will be the basis in modelling at the ANP methods. DEMATEL processing are consist of several stages, finding a original impact matrix criteria and subcriteria, searching for the direct impact matrix that have been normalized, looking for a total impact matrix and deciding threshold value to get map of impact diagraph.

\subsection{Application of ANP}

After doing the calculation by the method of DEMATEL to get relations between criteria and subcriteria, next is making models of ANP network uses Super Decision software based on a map of impactdiagraph. In addition to a map of the impact-diagraph, can clarify the modelling network ANP.

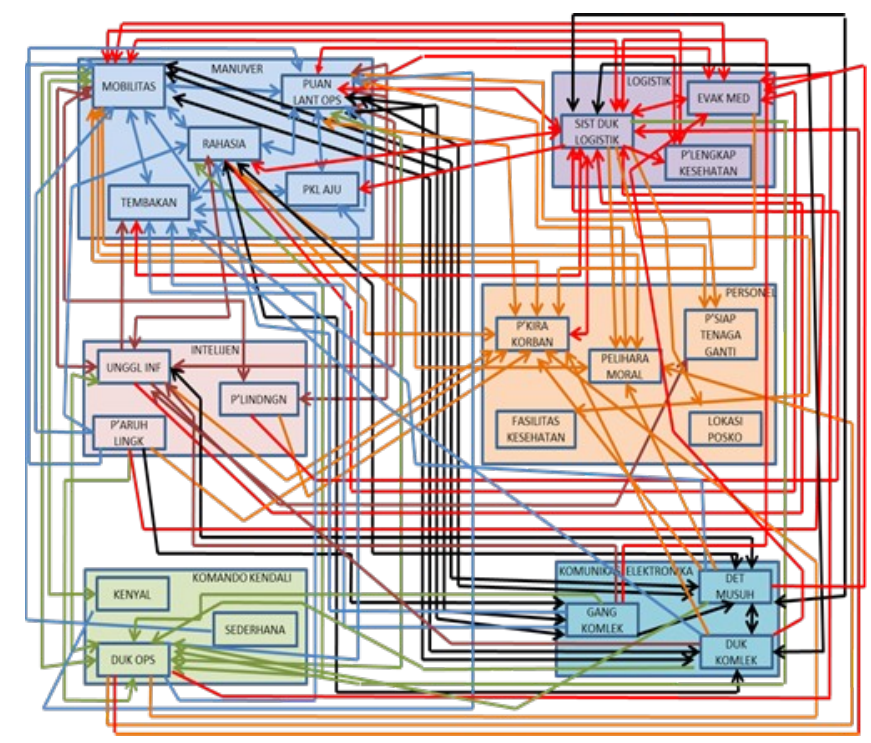

Figure 4.2 subcriteria relations

In Figure 4.2 above described the relationship innerdependence and outerdependence on the whole cluster (criterias) and there are elements (subcriterias) in it according to the arrow that had been described. Innerdependence is the relationships between elements in a cluster, whereas the connections between different elements of the cluster are called outerdependence. An example is the relationship between the interplay of elements (subcriteria) Mobility and Logistical Support Systems. Mobility greatly affects the amount of Logistical needs because the logistics are very supportive for mobility in Amphibious Operations. The relationships between subcriterias, result of the DEMATEL data processing in Figure 4.2 is the basis for the ANP Network model using the Super Decision software

Questionnaire drawn up based on the relationships between ANP criteria that has been obtained in advance by the DEMATEL method of impact-diagraph map. Questionnaire is composed of a question in the form of pairwaise comparison between criteria, or subcriteria an election of CoA alternative, either innerdependence or outerdependence in accordance with a previously specified for the selection of CoA alternative in the Planning procedure of Amphibious Operations. In the questionnaire the respondents give his judgement based on paired comparisons in accordance with a scale of 1-9 charging (Saaty, 1993).

5. Conclusions and Suggestions.

\subsection{Conclusions.}

Based on the results of research and data processing about selection manner of acting best in a procedure planning an amphibious operation by using DEMATEL and ANP hence conclusions may be drawn as follows:

1. There are 4 primary criteria, in the Course of Action namely the criteria operation, logistics, personnel and communications electronics. Operation criteria divided into three subcriteria and 
lowered into 11 sub subcriteria. Criteria logistic, personnel and communications electronics subkriteria, each divided into 3, 5 and 3 subkriteria.

2. The scale of priority the results of data processing is as follows: priority 1 are alternative of CoA 1 with weights value 0,430712 , priority 2 is alternative of CoA 3 with weights value 0,312294 and priority 3 is alternative of CoA 2 with weights value 0,256993 .

3. Primary criteria who gains the greatest weight priority in election of CoA on each criteria are mobility sub subcriteria with weights priority of 0,157694 (operation criteria), logistical support system subcriteria with weights priority of 0,159927 (logistics criteria), victims approximating subcriteria with weights priority of 0,091237 (personnel criteria) and enemy detection with weights priority of 0,067640 (communication and electronics criteria).

5.2

\section{Suggestions.}

1. Combination between a method of DEMATEL and ANP can be applied on the 7th stage of military decision-making process in the planning process of an amphibious operation, namely the process of comparison of $\mathrm{CoA}$ to determine the best $\mathrm{CoA}$ will be elected in order produce a decision which is quite objective, transparent, flexible and accountable manner.

2. A method of DEMATEL and ANP can also be used in the process of decision-making about the other problems like the determination of the Naval bases or the determination of instrumental weapons systems and other strategic decision-making that have multicriteria.

3. Suggestion for next researchers is making the interface program that can be used as an instrument for election of $\mathrm{CoA}$ in a planning process of an amphibious operation to be more easy for users, in this case the participants an amphibious operation exercise, so that it can produce the election of CoA quickly, accurate, objective and accountable.

\section{Key References.}

Fontela, E. and Gabus, A. 1973. DEMATEL, innovative methods, Technical report no. 2, Structural analysis of the world problematique. Battelle Geneva Research Institute.

Jaiswal, N.K. 1997. Military Operation Research: Quantitative Decision Making. Massachusetts: Kluwer Academic Publishers.

Mabes TNI. 2013. Doktrin TNI Operasi Amfibi. Jakarta: Mabes TNI.

Saaty, T. L. 1993. Pengambilan Keputusan Bagi Para Pemimpin (Terjemahan). Jakarta: PT. Pustaka Binaman Pressindo.

Saaty, T. L. 2001. “Decision Making With Dependence and Feedback The Analytic Network Process (2 ${ }^{\text {nd }}$ ed.) ".Pittsburgh: RWS Publication.

Seyed-Hosseini, S. M., Safaei, N., dan Asgharpour, M. J. 2005. Reprioritization of failures in a system failure mode and effects analysis by decision making trial and evaluation laboratory technique. Reliability Engineering and System Safety, 91(8), 872-881.

Yang, Leu dan Tzeng. 2008. A Novel Hybrid MCDM Model Combined with DEMATEL and ANP with Applications. International Journal of Operations Research Vol. 5, No. 3, 160-168 (2008). 